\title{
On Issue of Semantics and Pragmatics of Reflexive Constructions
}

\author{
Natalia A. Korepina* \\ Institute of Linguistics and Cross-Cultural Communication, Irkutsk National Research Technical University, Irkutsk, Russia
}

\begin{abstract}
The article describes semantics and pragmatics of reflexive constructions. Common notes on the semantics of reflexivity are given. Reflexivity reflects specific subject-object relationships demonstrated in explicitly and implicitly reflexive constructions. Implicit reflexivity is discussed of a relatively small class of verbs in English. It is stated that the full referent identity of an anaphora pronoun and personal antecedent in the position of the subject is not obligatory. Different standpoints on the nature of reflexivity are distinguished. The existence of a special type of referential identity of a reflexive anaphora and an antecedent word is substantiated, when one and the same referent is interpreted by these linguistic units in a different way carrying out different semantic and syntactic functions in a sentence. Moreover, an antecedent and an anaphora turn out to be united at the level of the semantic structure. In the syntactic structure, the anaphora and an antecedent word prove to be referentially non-identical. Using psycholinguistic analysis, reflexive constructions in English are divided into introspective and descriptive. The strangeness of reflexivity is in the use of a reflexive pronoun, conditioned by an aspectual-temporal form of a verb.
\end{abstract}

\section{Common notes on reflexivity semantics}

The place of reflexive is indefinite in the English Grammar. Reflexive constructions, phrases, forms of reflexive voice are referred to the category of reflexives. According to E.A. Genuisiene, there are more than 1500 verbs with oneself registered in different dictionaries [1, p. 179]. Semantically reflexivity is a category of the sentence, because it reflects specific subject-object relationships, where a subject and object referent is partly or fully the same. A reflexive construction is one, in which the subject and object refer to the same person or thing. Many languages, like English, have a set of reflexive pronouns distinguished in person and number (myself, yourself, himself etc.); others, like French, German or Latin, draw a distinction between reflexive and nonreflexive objects only in the third person, as follows: Maman me lave : Je me lave; Mummy is washing me: I am washing myself; Maman la lave : Maman se lave; Mummy is washing her : Mummy is washing herself. There are other languages which use the same reflexive pronoun with all persons and numbers. For example, Russian uses either the suffix -sja ( $-c я)$ or the pronoun sebja (себя).

According to a widespread point of view, a reflexive construction is one, in which a subject and an object are coreferential, the constructions, in which a reflexive pronoun does not take the position of an object (or this position is one of the possible positions, not influencing the common meaning of the whole construction), are not reflexive.

The constructions like I washed myself, He shaved himself and so on are not always considered to be reflexive, because they are supposed to have the meaning, common with a meaning of a proper nonreflexive construction: I washed, he shaved and so on. On the other hand, such point of view is proved by the dictionaries 6 in which any semantic distinction between two types of constructions is not recorded:

Mr. Barry is able to wash, prepare limited snack meals and dress himself.

Once they had left, he dressed and returned to where he had left his car.

'Just behave, Tom,' he said.

Generally, everybody seemed to be behaving themselves (http:// en.oxforddictionaries.com, date of access: 18.03. 2018).

At the same time in some cases, illustrations are given in a dictionary article without any alternative, for example, Take my advice, and go to-bed - hide yourself! The water was cold and she only had a sliver of soap to wash herself with. He washed, shaved, and had breakfast (http://search.ox.ac.uk, date of access: 18. 03. 2018).

Besides, from the above verbs, behave has a dictionary mark refl. (reflexive), when other verbs do not have such a mark.

* Corresponding author: cosmir@yandex.ru 
An explicitly reflexive sentence is one in which the identity of subject and object is overtly marked, either in the form of the object pronoun or in some other way, for example, by the use of a particular suffix, prefix or infix, attached to the verb-stem.

Thus, He killed himself by contrast with He killed him is explicitly reflexive. The same thing is with the sentence: He washed himself. However, it is a characteristic feature of English that many verbs can be used in reflexive sentences without the occurrence of an object pronoun. He never shaves before lunch exemplifies this usage and it is for that reason described as implicitly reflexive. In fact, shave is very rarely used in explicitly reflexive constructions - most commonly perhaps in the sentences like I don't mind shaving others, but I never shave myself, where the occurrence of myself is required for the contrast with others.

The implicitly reflexive construction is commonly found with wash, which may also be explicitly reflexive, but not with dry. He dried in the Sun can be interpreted as an intransitive sentence (non-agentive) or as a pseudo-intransitive sentence with objectdeletion e.g. He dried the dishes; He dried the clothes; but probably not as implicitly reflexive, equivalent semantically to He dried himself in the Sun [2, p. 116].

Implicit reflexivity would seem to be restricted in English to a relatively small class of verbs. Moreover, it is not always clear whether a particular sentence exemplifies implicit reflexivity or the more general kind of object-deletion [2, p. 116].

A reflexive construction is opposed to all other constructions with a given verb by the following indication: asymmetry/symmetry of relations between linguistic units and units of the referent level. The peculiarity of a reflexive construction is that despite what noun - functional, relative, identificatory - is in the place of a subject, a reflexive pronoun refers to that semantic part of the antecedent word, which can be denoted person, human being in the wide sense of the word [2, p. 116].

However, in a linguistic way, one and the same referent is differently explained: as a subject and object of a physical action, as a subject and object of perception, as a subject and object of spiritual activity and so on. This means that the full referent identity of an anaphora pronoun and personal antecedent in the position of the subject is not very obligatory. Though this fact was taken into account long ago [3, p. 620$623 ; 4$, p. 26-27], morphological concepts of reflexivity could not explain the existence of the constructions, in which a reflexive anaphora pronoun refers to different parts of the personal antecedent (to the parts of the body, things, traits of character): John shaved himself. John buttoned himself. John spent himself bankrupt. John controlled himself and his voice [5, p. 47].

John and himself here are not identical because in the first sentence it runs that John shaved only a part of his face, in the second - he buttoned his coat or jacket, in the third one - he spent his money, and in the forth - himself cannot be related to John because there is a combination of words his voice, which is deducted from the whole meaning of the personal antecedent, though in reality a voice and a face are inalienable parts of one thing. These constructions are not exceptions in the language; they are regular and can be formed with many groups of verbs. Referential identity of an anaphora and antecedent is likely to be an exception.

Basing on the semantics of lineal syntactic analogues of a derived unit, N.A. Janko-Trinitskaya gives prominence to the verbs of included transferred and excluded objects. Firstly, the meaning of the reflexive verb in comparison with the meaning of the underlying verb becomes wider at the expense of including in its semantics, except the meaning of the underlying verb, the meaning of the object of this underlying transitive verb in a more generalized aspect.

Thus, a reflexive verb means underlying verb + the object of this underlying verb $[6$, p. $172 ; 7, \mathrm{p}$. 176].

Pronominalization implies availability of paradigmatic relations between a reflexive and a transitive construction. For example, in Russian: $\mathrm{OH}_{H}$ зажмурился - $О н$ зажмурил глаза; Он причесался - Он причесал волосы; Он закабалился - Он закабалил себя. In English there are the following constructions like He restrained himself He restrained his anger; He buttoned himself - He buttoned his clothes [5, p. 48].

However, the paradigmatic approach can be relied on in the cases with the only possible complement like $О н$ зажмурил глаза, Он зажмурился (He closed his eyes tight), but this approach is insufficient, in case the verb permits the variety of the object: $O H$ причесал бороду, усы, волосы (He combed his beard, moustache, hair). That is why singling out of the lineal analogues (word-combinations), which are synonymous to reflexive verbs, did not clarify the essence of the process of derivation. As in [5, p. 49], the following points were not explained:

1) how one and the same reflexive element pronominalizes quite different objects;

2) where the listener gets the information about them from, if they don't exist in a surrounding context;

3) why some sentences with some objects are easily good to reflexive pronominalization: $\mathrm{OH}$ потратил деньги - Он потратился (He spent his money; He spent himself bankrupt); and others are not good to it at all: Oн причесал бороду/собаку (He combed his beard/dog) - Он причесался (Hе combed his hair; He combed himself).

Depending on the present interpretation of referential identity of a subject and object, two questions are the centre of attention:

1) to what extent is this referential identity absolute?

2) where is the information of these very objects derived from?

Trying to answer these questions, we can come near to the interpretation of transitivity in general. 


\section{Different standpoints on the nature of reflexivity}

There are a lot of disputes concerning reflexive constructions in English. Different standpoints on the meaning of reflexivity and different classifications of reflexive constructions exist.

L.M. Kovalyova supposes that the form of reflexive verbs and constructions in the IndoEuropean languages, which possess a reflexive element in their composition, indicates the transformation of reflexivization on the basis of outcome of these structures. The term semantic identity should be considered otherwise [5, p. 49].

Analyzing reflexive constructions according to the rules of reflexivization transformation, the antecedent for an anaphoric reflexive element should be looked for within a reflexive construction because referentially identical elements must be found within one sentence [8, p. 367].

To explain semantics of a similar construction, it is necessary to suppose that the information about the antecedent is in the semantics of an antecedent word, in this case - in the semantics of a personal name.

The dual nature of semantics of a personal name was noticed in linguistics long ago in connection with the grammar of a part and a whole and peculiarities of their syntax usage. In the popular article "Mind and Body" A. Wierzbicka [9, p. 129-157] analyses different subjects from a semantic point of view in the sentences like John is dirty, John is kind, because in the first sentence the word John has to do with a physical object, and in the second one it doesn't apply to the physical object at all. Taking this fact as a basis, she protests against J. Katz's analysis according to which the semantics of the word man is always a combination of the indications human and physical object [10, p. 155]. Also she is against P. Strawson's opinion that person is a particular primitive semantic unit, to which physical and mental predicates are related [11, p. 3]. According to A. Wierzbicka, the notion of a person cannot be treated as primitive because it can be divided into two elements, which can be spoken about separately and which do not substitute each other: John hates himself does not mean that John hates his body, and John hates his body cannot be transformed into the sentence: John's body hates John [9, p. 132].

By A. Wierzbicka, the word $I$ has four different applications:

1. In the sentences like I am in pain, I believe, I want the word $I$ does not have an independent meaning;

2. In the sentences like I believe in God, I am ambitious, I like Jim, I means this person;

3. In the sentences like I am heavy, I am dirty, I am short it means this body;

4. In the sentences like I see, I am walking, it is a stenographic reduction, covering various combinations of three preceding sentences [9, p. 135].

It is observed in [9] that the identification of a person depends, first of all, on the identification of a body. That's why sentences like John believes that ... , John hates Mary can't be transformed into John's mind believes that... , John's mind hates Mary. The indication of non-subjectness exists in the semantics of a personal name even in the sentences with physical predicates like John is dirty for:

1) a body of a living person isn't to be put in one row with lifeless things and objects, and the following substitution leads to appearance of a polysemantic sentence: John was dirty - John's body was dirty (in the last case the following interpretation of the sentence is admitted: John was dead);

2) the whole person is characterized indirectly, speaking about his body and the sentence John is dirty informs not only about John's body, but also about John in the whole;

3) separating actions or states of a body from its spiritual source, it is essential to underline this using body, as it is in the description of the brawl between two people maddened with rage:

He lay pressed hard against his adversary, his body adjusting itself to its own pure purpose of choking the other man (Lawrence, http://www.learnlibrary.com/sons-lovers/, date of access: 02. 03. 2018).

Exactly the indissoluble ties between object and acting source in the semantics of personal names made it possible for N.D. Arutjunova to speak about a dual semantic status of personal names, because they belong simultaneously to the class of object names and to the class of personal names. So, they very easily occupy the positions, assigned to the object and event (predicate) actants [12;13].

Multiplanned nature of semantics of personal names is very obvious analyzing its substitute (one)self, which can denote a person all himself, but also consisting of many parts:

"But a woman only works with a part of herself. The real vital part is covered up.” asked.

"But a man can give all himself to a work?" she

"Yes, practically." "And a woman only the unimportant part of herself?"

"That's it"

(Lawrence, http://www.learnlibrary.com/sons-lovers/, date of access: 02.03. 2018).

In giving to the character of his invention flesh and bones he is giving life to that part of himself which finds no other means of expression (Maugham, https://americanliterature.com/author/williamsomerset-maugham/book/the-moon-and-sixpence/, date of access: 02. 03. 2018).

Probably, the existence of many indications in Self allows us to speak about the best and the worst parts of $I$ and even to deny the identity of a real $I$ and a visible one. In this case the equality of oneself and an antecedent person is denied: I've never been myself or lived my own life at all. She isn't herself. She'll soon be herself again (Maugham, https://royallib.com/read/Maugham_William/Theatre. $\underline{\mathrm{html}}$, date of access: 02.03. 2018). It makes a man a little more than himself, and at the same time a little less. He ceases to be himself (Maugham, https://americanliterature.com/author/william- 
somerset-maugham/book/the-moon-and-sixpence/, date of access: 02. 03. 2018).

Besides, oneself can possess not only subject, but also event semantics, it can be proved by the following facts:

1). Oneself is in one row of homogeneous compliments with event and subject names: But he couldn't face himself, Susie, their life or his problems (Davidson, https://books.google.ru/, date of access: 02. 03. 2018).

2). Oneself can be a generalizing word for the names with event semantics. In the novel "Sons and Lovers", written by D. Lawrence, Paul, tired of his personal troubles and diseases, went with his friend to a neighbouring town for four days to have a rest. He is glad to forget everything: Paul was like another man. None of himself remained - no Clara, no Mirriam, no mother that fretted him (Lawrence, http://www.learnlibrary.com/sons-lovers/, date of access: 02. 03. 2018 ).

Himself unites here the subject on a formal level and the event units - on a semantic one: relations with Clara, Miriam, mother, filling all his thoughts and feelings before his departure.

3). A direct description of oneself is realized with the help of sentences, but not words: How can one describe a human being "justly"? How can one describe oneself? With what an air of false coy humility, with what an assumed confiding simplicity one sets about it! "I am a puritan" and so on. Faigh! How can these statements not be false? Even "I am tall" has a context (Murdoch, https://www.ereading.club/bookreader.php/104708/blackprince.pdf, date of access: 02. 03. 2018).

Following [5, p. 52], the personal name is not an antecedent for an anaphoric reflexive element in the full sense. It is a certain seme in its rich semantic structure. An antecedent seme is put into a name by a verbal predicate. So, the predicate button includes the seme Clothes into the personal actant, with what the anaphora correlates: (Person, having clothes) + Button + self $\rightarrow$ buttoned oneself. The predicate shave includes the seme hair on the face into the actant, with which the anaphora correlates: (Person, having hair on the face) + shave + self $\rightarrow$ shaved oneself. The condition of logical existential presupposition in such cases is considered to be fulfilled beforehand: it is implied by existing state of things, when all people are dressed, have their hair done, have money, etc.

Not always the natural division of the world is reflected in a reflexive construction with absolute precision. Sometimes the term of inalienable or essential quality is treated by the language very deeply, confer the sentence: Some of the oldest and wisest citizens had dug themselves in as for a state of siege [5, p. 53]. Here the citizens had dug themselves means the citizens had dug their houses, yards, yard buildings. On the other hand, the seme a part of $a$ body is not always to be reflexivized. For example, a person can shave any part of his body, but in this case the parts should be mentioned:

I do not enjoy shaving my legs or underarms (https://collegecandy.com/2014/04/03/why-didwomen-start-shaving-their-underarms-and-legs/, date of access: 15.03. 2018).
The foregoing facts theoretically substantiate existence of a special type of referential identity of a reflexive anaphora and an antecedent word, when one and the same referent is interpreted by these linguistic units in a different way, which carry out different semantic and syntactic functions in a sentence. In addition, an antecedent and an anaphora turn out to be united at the level of the semantic structure, and in the linguistic structure the anaphora and the antecedent word prove to be referentially non-identical. Consequently, it can be said about complete and incomplete, or partial, referential identity of a reflexive anaphora and an antecedent word [5]

Reference [14] aims at determination of the status of a reflexive pronoun: whether it is an independent member of the sentence with its syntactic function or a component of a predicate. In the last case, it can be said about the existence of the reflexive voice in Modern English. N.M. Aidinyan uses psycholinguistic analysis in her interpretation of reflexivity and divides reflexive constructions in English into introspective and descriptive. Introspective constructions are constructions in which the action is performed by the doer from inside of a reflexive construction, for example, I hurt myself. Descriptive constructions are constructions in which the action is given in the description of an observer from outside of a reflexive construction, for example: "You contradict yourself!» said Ivan, pondering (Dostoevsky, www.lingvolive.com, date of access: 02. 03. 2018)

Using the method of the semantic-syntactic complex analysis, the author comes to the conclusion that since a reflexive pronoun is rarely grammatized, as an object stands out distinctly in a reflexive construction, it means that the category of the reflexive voice does not exist in Modern English.

T.I. Desherieva supports this idea in her monograph [15, p. 88]. She supposes that the reflexive is not a special type of voice, because its formation is accompanied by unpurposive elimination of the second actant and identification of its denotat with that of the first actant (subject). In the system of voice oppositions, the reflexive is, by T.I. Desherieva, a special case of the active voice, its reduced form.

According to A.V. Kravchenko [16], the strangeness of reflexivity is the following: the use of a reflexive pronoun is somehow conditioned by an aspectual-temporal form of a verb. So, both the variants of the construction in the sentences are alike. He hid (himself) in the mountains is characterized by a native speaker as equal, but if we change the Past Simple for the Past Continuous, the non-reflexive construction is more preferable: He was hiding in the mountains, and the use of the reflexive pronoun in this case is characterized as unusual.

Let us look at subject-object constructions with a direct and prepositional object, where the object has a certain character: (1) She had her fiancé beside her. (2) She was beside herself with rage [16, p. 94]. The formal difference between these constructions (her/herself) is explained in grammar books by the fact that it reflects the distinction between a direct and a metaphoric meaning. The metaphor in (2) appears due to the use of a reflexive pronoun. The reflexive 
pronoun does not correlate with the subject she, but with one of its manifestations, which is, in this case, inner $I$ or psyche. This $I$ divides a syncretic subject into two natures: body and psyche. As a result, the following sense arises that the existence of an object indication, usually not possessing an external (observed) manifestation.

The spatial characteristics of one object in respect to another one is given in sentences (3) John Olsen walked in and closed the door behind him, (4) They placed their papers in front of them [16, p. 94]. In (5) She looked around her and (6) She looked around [16, p. 94], it runs about a spatial description of object motion in regards to a starting spatial position of the same object, besides the existence or the absence of the pronoun her does not influence a common meaning of the construction, as in the case with implicitly reflexive verbs. The use of a reflexive pronoun in constructions like (3-6) is impossible, because the spatial characteristics of an object is given in respect to another object as a homogeneous being essence, i.e. the observed spatial position of the objects is described, but nothing more.

Let us consider the following sentences:

(7) "That Joe Namath", he muttered as he pushed the New York Times to one side [16, p. 94];

(8) "And hope the other side doesn't come after us while we're eating our dinners", he muttered to himself as he entered his small cabin [16, p. 94].

The difference between these two examples is as follows: in (7) the fact of realizing speech activity without indication of its purpose is established, whereas in (8) the absence of an addressee as such is pointed out. The meaning of the construction he muttered to himself in a prototypic sense is spatial, since the performed action of speaking is directed not to the body he, but to its spiritual and thinking manifestation (psyche). An onlooker cannot affirm this; that is why the phrase He muttered to himself can have an assertive character only from the point of view of the subject of the action.

A prepositional object with a spatial meaning can have one of two meanings: a physical personality of a subject (in that case a reflexive pronoun is required to reflect the co-referentiality between a subject and a prepositional object), or physical surroundings of a subject (this meaning is defined by a context and needs using a non-reflexive pronoun), for example, John searched around himself $(\neq$ him) for the mosquito bite that was itching him so terribly, but John searched around him (himself) for the store he had tripped over [16, p. 99].

The sentence Charles pulled the cloak around him can be interpreted so: A influenced B, as a result B changed its spatial position in a certain way in respect to $\mathrm{A}$. The sentence Charles pulled the cloak around himself has such an interpretation: A influenced B, as a result $\mathrm{B}$ changed its spatial position in a certain way in regards to A, satisfying a certain need, experienced by A. In other words, in the first case, Charles' action is described on somebody's part, whereas in the second one the situation is described from Charles' part, because nobody else can know, what kind of need Charles experiences [16, p. 100].
Let us turn to the constructions with implicitly reflexive verbs like wash. Describing this or that situation, the speaker is at the same time an observer, who ascertains this or that state of things proceeding from what he sees. Such actions like washing, dressing, shaving etc. can be characterized as implicitly egocentric.

A list of the verbs, found in parallel constructions, is not limited by egocentric verbs, for example: She dropped into a chair, utterly worn out; She dropped herself into a chair, utterly worn out [16, p. 102]. In this case, a native speaker chose the non-reflexive construction, but the reflexive one was not rejected. The reflexive constructions of a considered type are found in a written discourse together with nonreflexive constructions. The above-mentioned examples with the verb drop give a true visual notion of a primary function of reflexive: a reflexive pronoun is an explicator of the intention, indicated by a verb [16, p. 102].

In the statement She dropped into a chair ... the situation, entirely based on its perception by an observer, is described: the object $\mathrm{X}$ changed its position in a certain way with regards to the object $\mathrm{Y}$, besides the attribute group utterly worn out is characteristics of the object X from an observer's position. In the statement She dropped herself into a chair ..., there is an additional sense: the object $\mathrm{X}$ realized the intention of making this action. The affirmation of the existence of the intention of making the action drop can depend on precise knowledge, which an observer can't possess in principle. This knowledge belongs exclusively to the subject of the action: The sea washes the base of the cliffs; He washes his clothes; He washes his face; Huge waves washed over the deck; He washed over the sink; He washed [16, p. 103]. It is obvious that different meanings of the verb wash go back to one semantic prototype, connected with the idea: water influences an object. The same can be said about the verbs shave, dress and so on. Speaking in a different way, the above-named verbs are not immanently intentional, and it is reflected in their reflexive use. In the sentence Go and wash yourself the use of the reflexive makes an additional sense: the indication on necessity for the subject to have an intention of making an action, the subject doesn't have any from the speaker's point of view.

\section{Conclusion}

From the above analyzed authors' points of view and the discussed examples, it can be concluded that reflexive pronouns demonstrate such richness of semes in the content of a personal name, that its explanation claims a new approach to the semantics of a word in general. Moreover, there are special relations between an anaphora and an antecedent word creating favourable conditions for infinite shifts in the semantics of the verbs with oneself and reflexive constructions, which are always striking examples of lexicalization of grammatical relationships. The use of a reflexive pronoun in the constructions marked by the indication an observer is 
functionally relevant. A reflexive provides the indication on intentionality of an action, expressed by a verb, and, together with other grammatical phenomena, is included in the system of linguistic means forming an indicatory field of language.

\section{References}

1. E. Sh. Genuisiene, The typology of reflexives (Mouton, Berlin, N.Y., Amsterdam, 1987)

2. J. Lyons, Semantics (Cambridge University Press, Cambridge, 1977)

3. V.V. Vinogradov, The Russian language (Grammar Theory of Word) (Uchpedgiz, M.; L., 1947)

4. V. P. Nedyalkov, Diatheses and voice, 21-33, (1975)

5. L.M. Kovalyova, Semantic and pragmatic aspects of English sentence (ISU, Irkutsk, 1992)

6. N.A. Janko-Trinitskaya, Reflexive verbs in modern Russian (Academy of Sciences USSR, M., 1962)

7. E.E. Kordi, Problems of linguistic typology and language structure, 171-177 (1977)

8. W. Abraham, Terminologie zur neueren Linguistik (Max Niemeyer Verlag, Tübingen, 1974)

9. A. Wierzbicka, Syntax and Semantics 7, 129-157 (1976)

10. J.J. Katz, The Philosophy of Language (Harper and Row, N.Y., 1966)

11. P.F. Strawson, Individuals ( Methuen, London 1959)

12. N.D. Arutyunova, Proceedings of Academy of Sciences of USSR, 34 (4), 341-350 (1975)

13. N.D. Arutyunova, Sentence and its meaning (Logical and semantic issues) (Nauka, M., 1976)

14. N.M. Aidinyan, Reflexive constructions in modern English (L., 1983)

15. T.I. Desherieva, Subject and object relations in the languages of different structures (Nauka, M., 1985)

16. A.V. Kravchenko, Philological Sciences 4, 92105 (1995) 